\title{
Experiencias religiosas familiares e iniciación cristiana en Bogotá: diálogos academia-pastoral ${ }^{1}$
}

\section{Family religious experiences and Christian initiation in Bogotá: academia-pas- toral dialogues}

\author{
Camilo Andrés Barrera Alvarado ${ }^{2}$ \\ Johnier de Jesús Montoya Castaño ${ }^{3}$ \\ Diana Carolina Silva ${ }^{4}$ \\ DOI: 10.29151/hojasyhablas.n20a7
}

\section{Resumen}

Este artículo presenta los resultados de un ejercicio interdisciplinario acerca de los procesos de crianza en la vida familiar, particularmente la transmisión de la fe. Desde la racionalidad hermenéutica se optó por la triangulación metodológica, articulando la elaboración de un Estado del Arte, la aplicación de encuestas a 857 participantes (niños, niñas, jóvenes, padres y madres) en catequesis de primera comunión y confirmación, y el desarrollo de un grupo focal con catequistas. Se identifican relaciones entre los procesos de crianza familiar (creencias, pautas y prácticas) y la transmisión de la fe (dimensiones objetiva, simbólica, subjetiva y afectiva de la experiencia religiosa), que permiten conocer las formas de configuración familiar de quienes participan en catequesis, su comprensión de Dios y la relación que establecen con él, además de la vivencia de la experiencia religiosa en su cotidianidad. Las categorías de experiencia religiosa y experiencia familiar se relacionan dialécticamente al interior de las familias y se expresan en los resultados expuestos, promoviendo la reflexión en los procesos pastorales para responder a la tarea evangelizadora en contextos de transformaciones familiares.

Palabras clave: Experiencia religiosa; creencia religiosa; catequesis, familia; pautas de crianza.

\begin{abstract}
The article presents the results from a multidisciplinary research about the family life during upbringing, particularly about the way in which faith is transmitted. From a hermeneutic rationality, we decided to carry out a methodological triangulation, combining the development of a state of the art, the application of 857 surveys (to boys, girls, young, fathers, and mothers) in catechesis preparing for First Holy Communion and for Confirmation, and the focus groups with catechists. We find relationships between the upbringing processes in families (beliefs, patterns, and practices) and the transmission of faith (in objective, symbolic, subjective, and affective dimensions of the religious experience), that enable us to understand the family configuration of the participants in catechesis how these participants relate to God, and how they experience religion in their day-to-day lives. The categories of religious experience and family experience have a dialectic relationship within families and express in the findings presented, promoting reflection about pastoral processes to answer to the evangelizing task in contexts of family transformation.
\end{abstract}

Keywords: Religious experience; religious belief; catechesis; family; parenting patterns.

\footnotetext{
${ }^{1} \mathrm{M}$ Artículo resultado de investigación

${ }^{2}$ Magíster en Estudios y Gestión del desarrollo, estudiante de Doctorado en Educación en la Universidad de La Salle de Costa Rica. Docente del programa de Trabajo Social de la Unimonserrate. Miembro del grupo de investigación de Estudios de contextos y realidades sociales. Correo: camilo.barrera@unimonserrate.edu.co. ORCID: https://orcid.org/0000-0003-4755-9410

${ }^{3}$ Doctor en Teología del Pontificio Instituto Teológico Juan Pablo II para las ciencias del Matrimonio y de la Familia (Pontificia Universidad Lateranense de Roma). Docente del programa de Teología de la Fundación Universitaria Monserrate Unimonserrate. Miembro del grupo de investigación de Estudios de contextos y realidades sociales. Correo: centrofamiliajp2@unimonserrate.edu.co

${ }^{4}$ Terapeuta Familiar Sistémica, Magíster en Gobierno y Políticas Públicas de la Universidad Externado de Colombia, Trabajadora Social de la Universidad Nacional de Colombia. Correo: dianasilvatsocial@gmail.com
} 


\section{Introducción}

El proyecto de investigación 'Representaciones sociales de la experiencia religiosa y su relación con pautas y prácticas de crianza en la transmisión de la fe' constituyó un ejercicio dialógico interdisciplinario ${ }^{5}$ en torno a los procesos de crianza en la vida familiar, específicamente desde la transmisión de la fe como una de las dimensiones desde las que se desarrollan estos procesos, y en el que confluyen no solo los contenidos doctrinales que hacen parte de la denominación religiosa, sino también las experiencias religiosas de los miembros de la familia, caracterizadas por la diversidad y la multiplicidad según las tradiciones, historias familiares y contextos sociales en los que se desarrollan. Así, el equipo investigador articuló elementos de las ciencias sociales y la religión, con la intención de aportar a la academia y a la pastoral desde las relaciones entre la experiencia familiar -expresada en términos de procesos de crianza- y la experiencia religiosa -expresada en términos de transmisión de la fe-.

Acorde con la perspectiva sistémica, el proyecto constituyó un acercamiento reflexivo a la investigación social, un tejido de distintas miradas, saberes, comprensiones epistemológicas y metodológicas, que acompañaron el ejercicio y enriquecieron la interpretación y comprensión de la información recolectada, integrando para ello, entre el primer período de 2018 y el primer período de 2019, a docentes y estudiantes de los programas de Teología y Trabajo Social ${ }^{6}$ (Escuela de Ciencias Humanas y Sociales), de la Especialización en Educación y Orientación Familiar ${ }^{7}$ (Instituto de Estudios en Familia), del Centro
Asociado de Estudios Teológico-Pastorales en Familia Papa Francisco, y familias y catequistas de 18 parroquias de la Vicaría Episcopal Territorial de Cristo Sacerdote (en adelante VETCS).

Para ello, fue necesario reconocer el entramado cultural donde se desarrolla la acción pastoral de la Arquidiócesis de Bogotá, que se da de distintas maneras, entre ellas, la iniciación cristiana y la pastoral familiar, donde muchas personas se acercan y comparten aspectos de su cotidianidad, los cuales contribuyen a configurar su experiencia religiosa individual, pero también la experiencia colectiva, comenzando por el grupo familiar. $\mathrm{Al}$ respecto, en el Plan de Evangelización de la Arquidiócesis de Bogotá se afirma que la ciudad capital "es la convivencia simultánea de múltiples ciudades invisibles y territorios urbanos, que se entretejen con las dinámicas de la globalización y los complejos procesos de desarraigo generados por las migraciones y el desplazamiento forzado" (Arquidiócesis de Bogotá, 2013, p. 12). Lo anterior llevó a que el equipo investigador se planteara la siguiente formulación: ¿Qué representaciones sociales de la experiencia religiosa se relacionan con las prácticas y pautas de crianza en la transmisión de la fe de familias participantes de procesos de iniciación cristiana?

Para responder fue necesario, en primer lugar, elaborar un Estado del Arte sobre la relación entre a) la experiencia religiosa, b) las prácticas y pautas de crianza, y c) la transmisión de la fe de las familias, desde perspectivas teóricas de las ciencias sociales y humanas y desde la acción pastoral de la Iglesia Católica, toda vez que el tema presentaba novedades para los integran-

\footnotetext{
${ }^{5} \mathrm{Al}$ ser un ejercicio interdisciplinario es importante enfatizar que el presente no constituye un artículo teológico. Así como se retoman algunos elementos de la teología (reconociendo que se habrían podido adoptar otros), se retoman elementos de otras áreas, para promover el diálogo necesario entre academia y pastoral.

${ }^{6}$ Graduadas que participaron como auxiliares de investigación: Daniela Andrea Curbelo Niño, María Alejandra Gutiérrez Gutiérrez, María Alejandra Pérez, Lina María Rincón Infante y Anlly Beatriz Rodríguez Jaraba

${ }^{7}$ Docentes: Andrea Mireya Jiménez Pinzón (2018-I) y Diana Carolina Silva (2018-II y 2019-I), y graduados que participaron como auxiliares de investigación: Diana Patricia Barbosa Velásquez, Nathaly Clavijo Loaiza, Wilson Pasto Arévalo y Ricardo Saba Sierra
} 
tes del equipo. Esto permitió al equipo construir sus categorías apriorísticas para aproximarse a las relaciones entre experiencia religiosa (entendida en la investigación desde el proceso de transmisión de la fe) y procesos de crianza (sintetizados en pautas y prácticas).

Las representaciones sociales no constituyeron una categoría teórica en el estudio, son los supuestos investigativos, entendidos como "afirmaciones previas, pero que no cuentan con el mismo peso referencial de las premisas y, por ello, solo pueden ser tomadas como antecedentes relativos para la investigación" (Cisterna, 2005, p. 64). El equipo investigador asumió que las representaciones sociales de la experiencia religiosa son "maneras específicas de entender y comunicar la realidad e influyen a la vez que son determinadas por las personas a través de sus interacciones" (Materán, 2008, p. 244-245) y dedicó el presente estudio a describir esas maneras específicas de expresar su afiliación religiosa, relacionándolo con las pautas y prácticas de crianza.

Se presenta a continuación el resultado de esta aproximación conceptual, precisando que su construcción se realizó a modo de grupo de estudio entre el equipo donde, a partir de algunas lecturas propuestas, se configuró el lugar de los observadores, es decir, desde dónde se enuncia la investigación. Sin desconocer las múltiples perspectivas desde las que se han abordado los conceptos sobre todo en la teología, disciplina en la que las categorías han sido desarrolladas con mayor profundidad, es importante precisar que se retomaron algunas posturas que, en el momento en que se realizó el estudio, favorecieron el diálogo entre ciencias sociales y religión, para abordar los procesos de crianza familiar.

\section{Experiencia religiosa}

El término "experiencia" ha sido estudiado desde la perspectiva antropológica y personalista por Karol Wojtyla (2011), quien manifiesta que la experiencia no se reduce a un conocimiento sensi- ble ni a una dimensión cognoscitiva de tipo racional, sino que implica a todo el sujeto y la conciencia de sí mismo en su interacción con la realidad. También desde el campo antropológico Guardini $(1997 ; 2016)$ menciona que la experiencia se comprende como un modo particular de encontrarse con el mundo, conocerlo y relacionarse, acto en el que el sujeto se siente implicado, y donde confluyen los diferentes dinamismos de la persona humana: el cuerpo, el afecto, la inteligencia y la voluntad.

Siguiendo esta línea de comprensión, puede afirmarse que la experiencia en general hace referencia a una cualidad por la que el sujeto es tocado y a través de la cual él toca y conoce la realidad, no sólo inmanente sino en cuanto "experiencia de lo sagrado" (Guardini, 1964, p.30). Como lo afirma Morales (1995), la experiencia lleva a centrar la mirada en la vida cotidiana, toda vez que "esta vida presenta habitualmente diferentes niveles y momentos de intensidad, $y,[\ldots]$ tal como lo ha consagrado la tradición católica, se halla abierta a importantes vivencias de Dios y de lo sobrenatural" (p.70).

Una reflexión significativa a propósito del tema en cuestión proviene de Sánchez (2015) quien señala algunas tensiones existenciales de la experiencia religiosa al tender un puente entre dos niveles de relación. El primero trascendente, que supera siempre al individuo y lo conecta con lo divino, y el otro inmanente e inmediato, que lo ubica en un contexto tejido de herencias culturales, tradiciones y creencias religiosas que terminan por configurar, en gran parte la identidad del sujeto a través de lo que hace y la razón del por qué lo hace, es decir el sentido. Es así como se puede afirmar que la persona, y por extensión la comunidad familiar, es "fruto de una tradición religiosa" que preexiste. Estas tensiones son elementos circulares de la experiencia religiosa en permanente contraste y relación entre: creatividad y estabilidad, espontaneidad e institucionalización, invocación y permanencia, de donde deriva que la religión no tiene un fin en sí misma, sino que es propiciadora 
de sentido de la existencia, siempre como experiencia personal. De hecho, toda religión es el espacio natural, cultural, histórico, pero no exclusivo, de manifestación y comunicación de la experiencia religiosa. Siguiendo a García-Alandete (2009), podría decirse que mientras la religión es la "religiosidad en su dimensión comunitaria, compartida e institucionalizada" (p. 119) y tiene en este campo su lado objetivo; la experiencia religiosa privilegia la relación personal del hombre con el misterio que aquella media.

Por su parte Corpas de Posada (2010), señala que la experiencia religiosa como encuentro con la trascendencia requiere un vehículo que le permita no sólo comunicarse sino interpretarse y resignificarse continuamente. Este medio es el lenguaje religioso, que, como todo lenguaje humano, se apoya en los símbolos para manifestarse y necesita, precisamente, un lenguaje simbólico para comunicarse. Aquí lo simbólico completa lo verbal con lo no verbal, lo describible con lo indescriptible, pero que, aun así, puede y quiere ser comunicado. Lo simbólico, en cuanto lenguaje religioso, media y manifiesta los profundos contenidos de la experiencia religiosa personal.

Para el equipo investigador, lo simbólico permitió hacer referencia a los ritos y signos (gestos, palabras, imágenes) por los que se expresa la fe en la cotidianidad de la vida familiar (Borobio, 2000), esto sin desconocer que, para la Teología, constituye un campo de estudio de mayor densidad.

En la experiencia religiosa, y el modo de significar el mundo y sus valores, incide tanto lo racional como lo intuitivo y efectivo según Vergote (citado por Corpas de Posada, 2010). De hecho, el conocimiento "experiencial" que produce esta, evidencia no sólo el componente racional e intelectual que lo nutre sino, principalmente, el proceso de integración subjetivo que se "vincula con el corazón y el sentimiento" (Corpas de Posada, 2010, p. 63). Es así como la experiencia religiosa permite al sujeto vincularse interior- mente a ciertas creencias y criterios de valor, no sólo por principio de autoridad, sino porque le resultan significativas, relevantes, reales. Sobre la experiencia religiosa, y el modo como implica todas las dimensiones del sujeto, sin olvidar su carácter objetivo, García-Alandete (2009) enfatiza en su aspecto "vivencial", afectivo, emotivo y fenomenológicamente "subjetivo" (p. 119-120). También Vergote entiende la experiencia religiosa como "captación profundamente afectiva de una realidad sobrenatural" (citado por Gallego, 2010, p. 39).

A partir de lo debatido en los grupos de estudio, el equipo propuso cuatro dimensiones constitutivas de la experiencia religiosa que, si bien dialogan entre sí, indican algunas especificidades complementarias del fenómeno religioso en el campo de la apropiación personal y de la vida familiar. Estas cuatro dimensiones son: lo objetivo, lo simbólico, lo subjetivo y lo afectivo. Se describe a continuación, para claridad del lector, como se comprendieron estas cuatro dimensiones en la presente investigación.

Lo objetivo como primera dimensión hace referencia al aspecto institucional de la experiencia religiosa, manifiesto en ritos, normas, doctrinas y estructuras de gobierno, por lo que conecta con el rol de la autoridad a la que la religión está vinculada en el orden trascendente. Sobre este aspecto hacen alusión García-Alandete (2009) y Sánchez (2015).

La segunda dimensión, lo simbólico, da cuenta de la expresión de la experiencia religiosa gracias a la riqueza del lenguaje verbal y no verbal. Esta dimensión evidencia no solo el universo de creencias, representaciones y significados en el ámbito religioso, sino el modo como estas se conectan con el mundo, moldeando al sujeto en su dimensión ética, y que son aprendidas en los procesos de crianza familiar. Vale la pena señalar que, si bien teológicamente el símbolo es un campo de mayor profundidad, en este estudio se comprende 
en un nivel instrumental, como expresión de la fe, toda vez que permiten comprender las representaciones que se construyen en las familias.

Sin embargo, haciendo alusión al campo teológico, son valiosos los aportes de Karl Rahner (1961 y 1964), quien según Dorronsoro (2014) distingue dos sentidos de símbolo: el "símbolo esencial o real" y el de "símbolo vicario", precisando al respecto:

El símbolo esencial es la "manifestación y tangibilidad histórica, espacial y temporal, en la que un ser, al ponerse de manifiesto, se anuncia, y al anunciarse se pone presente, originando esta manifestación que es realmente distinta de él"; y define el símbolo vicario como algo que remite a otra cosa por alguna semejanza o coincidencia entre ellas. Rahner añade que la noción de símbolo esencial es primaria u original, mientras que la otra es secundaria o derivada. La razón de esta distinción jerárquica se encuentra en que el símbolo real es constitutivo del ente - «el ente es por sí mismo necesariamente simbólico porque necesariamente se "expresa" para hallar su propio ser»-, mientras que el remitir a otra cosa es algo accidental o sobreañadido al ente. El símbolo esencial aparece así asociado a la "expresión" del ente, pero sin reducirlo al orden intencional porque el ente existe en cuanto se expresa (Dorronsoro, 2014, p. 2).

Junto a esta compleja aproximación al término símbolo en Rahner que tiene connotaciones teológicas y antropológicas trascendentales, con su ontología del símbolo "esencial" o "real" (Dorronsoro, 2014, p.1), otros autores hacen alusión al tema en el campo teológico desde una perspectiva litúrgica, evidenciando la relación entre símbolo y misterio, en cuanto los "símbolos sacramentales" son precisamente un modo particular de la comunicación entre la trascendencia y la inmanencia, lo invisible y lo visible, lo que evoca, precisamente, el origen griego del término $(\sigma v \mu \beta a ́ \lambda \lambda \varepsilon \imath v)$ que significa unir, como dimensión propiciadora del encuentro y la relación (Arocena, 2011).

Siguiendo lo anterior, para la teología los sacramentos (símbolos sacramentales) no son solo una representación que dependa de la significación e interpretación del creyente, sino que son una revelación del misterio, una actualización real de la presencia de Dios en un contexto litúrgico a través de signos visibles (palabras, signos y realidades materiales) mediante los cuales se comunican la gracia de Cristo a través la mediación de la Iglesia (Borobio, 2003; Schillebeeckx, 1971). Entonces, lo simbólico es un concepto complejo y polisémico que atañe a diversas aproximaciones desde el pensamiento humano. Precisamente en el marco de la teología litúrgica y sacramental el sacramento como símbolo tiene una especificidad particular, pues no sólo representa y expresa, sino que actualiza lo que significa al ser instrumento eficaz de comunicación de la gracia santificante (Sacrosanctum Concilium 59). La investigación tema del presente artículo, sin pretender reducir el término símbolo y sus comprensiones a un solo aspecto en detrimento de la eficacia sacramental en el campo teológico, se circunscribe en un horizonte distinto de las representaciones sociales, propio de las ciencias humanas y sociales.

La tercera dimensión es lo subjetivo de la experiencia religiosa, que corresponde al campo de la búsqueda personal de sentido y los modos y prácticas particulares como el sujeto se conecta con lo sagrado, sin estar vinculadas necesariamente a una institución religiosa ni sus normas directas, sin negar por esto el carácter comunitario y comunicable de la experiencia religiosa (Sánchez, 2015).

La cuarta dimensión, lo afectivo, es el campo más íntimo y personal de la experiencia religiosa, y se relaciona con el mundo de las emociones, de los sentimientos y afectos. Esta última dimensión podría ser descrita como el universo interno del sujeto que no sólo se vincula a ideas o principios, sino que busca relacionarse, pertenecer, sentirse vinculado a alguien inmanente o trascendente que oriente su vida y ayude a encontrar sentido al ser.

Finalmente, se describe el modo como el 
equipo investigador interrelaciona las cuatro dimensiones de la experiencia religiosa. Las dimensiones objetiva y simbólica son transmitidas culturalmente según la concepción religiosa, mediante prácticas que comunican implícita y explícitamente pautas y normas de comportamiento; las dimensiones subjetiva y afectiva de la experiencia religiosa evidencian el rostro concreto y personal de quien interioriza la creencia religiosa, en ocasiones afiliándose a la institución religiosa, y en ocasiones al margen, apropiándose del sentido de las normas y de las prácticas que genera. Mientras las dos primeras dimensiones son marcadamente comunitarias, las dos segundas, sin ser intimismo incomunicable, son principalmente demandas y búsquedas personales. Esta clasificación es parcial, no es categórica, pues la intención no es caer en reduccionismos que nublen la complejidad y las múltiples relaciones entre las dimensiones.

\section{Experiencia familiar}

Teológicamente, la familia se comprende como Iglesia doméstica (Lumen Gentium 11), identificación permite desarrollar una teología de la familia, pues si se reconoce "a la familia como la más pequeña comunidad eclesial, donde están presentes todos los elementos que caracterizan a la Iglesia” (Aros y Basualto, 2014, p. 164), se reafirma su identidad como una institución social y su identidad sacramental.

Esta convicción nace porque el matrimonio es la unión entre un hombre y una mujer bautizados, de modo que este vínculo natural es elevado por Cristo a la dignidad de sacramento (Código de Derecho Canónico, can.1055), lo que origina la vida familiar, pues desde ese momento nace una nueva comunidad que se vincula con la comunidad eclesial, constituyéndose así en la expresión más pequeña de la Iglesia. (Aros y Basualto, 2014, p. 165)

Al comprender teológicamente el papel de la familia dentro de la experiencia religiosa como Iglesia doméstica, es relevante identificar su rol formador y la relación que se establece entre fa- milia, educación y fe, por medio de la cual se generan diferentes escenarios educativos y roles docentes (padres de familia, catequistas, ministros ordenados, líderes laicales, entre otros) estos se caracterizan porque "la docencia se reconoce como un apostolado" (Nieto y Pérez, 2020, p. 89) que dinamiza el Munus Docendi de la Iglesia. Siguiendo a Pérez, et. al (2020) la lectura que se puede realizar del Concilio y del querer de la Iglesia, se encuentra en el respeto por la voluntad de los padres en la formación religiosa de sus hijos, siempre y cuando la misma esté mediada por un acompañamiento permanente que transite entre el testimonio y la práctica cristiana. Lo anterior reviste a la paternidad y maternidad de unas dignidades especiales que los constituyen como primeros gestores de la educación (Gaudium et Spes 48) y garantes del vínculo entre fe y educación en la formación de sus hijos (Dignitates Humanae 5). Por esta razón, en la práctica pastoral, el proceso educativo de la familia "procura la inserción cultural que le permite al cristiano involucrarse con los problemas del momento presente" (Pinto y Nieto, 2020, p. 50), para que este pueda construir "no sólo un saber por adquirir, sino también valores por asimilar y verdades por descubrir" (Documento de Aparecida 329)

Por su parte, Corpas de Posada (2006) realiza un ejercicio dialógico entre los presupuestos teológicos sobre la familia y los presupuestos antropológicos de la experiencia humana de la familia, lo cual constituye una tarea importante en la Iglesia para reconocer que "la familia, en cuanto experiencia humana, está condicionada por su entorno cultural" (p. 431), por lo que se puede afirmar que "no existe un modelo único y universal de ser familia" (p. 431), pues cada experiencia familiar es distinta. Sin embargo, señala también que no es una experiencia de mera cohabitación gracias a vínculos establecidos por un grupo de seres humanos; es necesario incorporar el componente afectivo y reconocer que "el dinamismo del amor hace a la familia cuna de la vida cuando la pareja llama a los hijos a la vida y asume la tarea 
de educarlos" (Corpas de Posada, 2006, p. 432).

Finalmente, la autora señala la necesidad de "tener en cuenta que la familia vive un momento de cambio y que la crisis de un modelo familiar está dando paso a otro, con la consiguiente tensión propia de todo cambio" (Corpas de Posada, 2006, p. 439); cambios que, desde la perspectiva de Sánchez (2018), "tanto en las formas de organizar como de hacer familia, ponen en cuestión la noción de "familia cristiana» como modelo funcional y deseable al resto de la sociedad" (p. 90), por lo que se hace necesario el diálogo permanente.

Aros y Basualto (2014), por su parte, realizaron una lectura eclesiológica de la familia. Su comprensión teológica implica que ella (la familia), debe manifestar los rasgos constitutivos de la Iglesia entera, y, por tanto, "todo lo que se diga de la Iglesia se puede decir de la familia, ya que ella es, propiamente, Iglesia doméstica" (p. 167). En este sentido, comprender desde la Iglesia a la Familia le confiere una identidad particular a la familia cristiana en la sociedad contemporánea.

Fruto de esta revisión, el equipo investigador observa que la comprensión de las familias como Iglesia doméstica, les otorga roles de liderazgo y responsabilidad a los padres de familia en la transmisión de la fe, de modo que, en la convivencia familiar, la persona se experimente como creada, amada y salvada por Dios, no solo como una acción sobrenatural, sino que se concreta en la experiencia humana. De este modo, en la vida familiar emerge el ambiente propicio para que se desarrolle la experiencia religiosa, a través de la relación de pareja, de la relación entre padres e hijos y de la relación entre hermanos y hermanas. Así mismo, la relación cercana entre las familias y la Iglesia favorece el desarrollo de este ambiente de fe, de ahí la participación activa en los sacramentos y en los espacios de preparación para ello, como lo son las catequesis pre-sacramentales.

Sin embargo, es preciso reconocer que esta realidad de Iglesia doméstica entra en tensión al comprender que los cambios económicos, culturales, políticos, sociales y tecnológicos contemporáneos afectan la vida familiar. Sus modos de conformación y de vinculación se están diversificando, y en esta multiplicidad la experiencia religiosa adquiere matices particulares que pueden interpelar la comprensión de Iglesia doméstica de la familia, en sintonía con la enunciación en plural de las familias que, desde las ciencias sociales se ha desarrollado, por las diversas maneras como se configuran. Estas reflexiones llevaron al equipo a preguntarse: ¿cómo viven las familias católicas en la actualidad?, ¿cómo se comprendería ser iglesia doméstica en el siglo XXI?, ¿cómo dialogan los procesos de catequesis y la liturgia con los cambios que están viviendo las familias hoy?, interrogantes que serían tenidos en cuenta en las etapas siguientes del estudio.

Para comprender la experiencia familiar, se abordó también la relación entre religión y vida familiar. Para ello se retomó un estudio publicado en Journal of Marriage and Family (Mahoney, 2010) en el que su autora buscaba explorar el rol de la religión, tanto positivo como negativo, en las relaciones maritales y parento-filiales, en los estadios de formación (creación de roles esponsales y parentales en las familias), mantenimiento (roles de las familias en el sustento de procesos familiares socialmente deseables y disminución del riesgo de divorcio, violencia intrafamiliar, infidelidad y abuso infantil) y transformación de las relaciones familiares (cambios fundamentales o procesos de angustia en las relaciones familiares), en 184 estudios publicados entre los años 1999 y 2009.

En sus conclusiones, señala la necesidad de transitar de una religiosidad genérica a identificar las prácticas y creencias específicas que mitigan o intensifican los problemas en las familias, sean tradicionales o no. Así mismo, señala que existe mayor evidencia de cómo la religiosidad influye en la formación y mantenimiento de relaciones familiares tradicionales o no, pero muy poca investigación sobre cómo la religión puede ayudar 
o perjudicar cuando las angustias familiares ocurren. Además, identifica tres conjuntos de mecanismos espirituales de integración con la religión que pueden influir en los estadios antes mencionados: a) relación con lo divino de un miembro de la familia, b) relación familiar impregnada de propiedades espirituales a nivel cognitivo o comportamental, $y, c)$ miembros de la familia en relaciones con comunidades espirituales.

En la etapa de formación, la autora señala que en la década de referencia los estudios privilegiaron la teorización de esta relación y evoca el término "familismo religioso" (religious familism), para hacer referencia a "la ideología de que la familia es la preciosa y central unidad del orden social y debería ser gobernada por imperativos morales religiosos" (Mahoney, 2010, p. 810), y que se sustentaba en discursos pro-nupcias, pronacimientos, diferenciados de roles de género, entre otros, que permitieron reforzar la comprensión de una "buena" familia. La religión promueve la procreación en las familias, encontrando estudios que evidencian que, a mayor vínculo personal con lo religioso, mayor tasa de fecundidad, especialmente en las mujeres. Respecto de los roles de los hombres en la crianza, la autora señala que existen pocos estudios. Si bien puede existir una relación entre la afiliación religiosa y la mayor inversión de tiempo en la crianza de los hijos, no existe suficiente evidencia al respecto.

En la misma etapa, y con relación a la definición de roles en la familia, la autora resalta que existen relaciones entre religión e índices de comportamiento, más que indicaciones actitudinales de cómo deben comportarse hombres y mujeres en la vida familiar. Por último, la autora señala que, si bien en el último siglo se ha presentado un aumento de la producción a favor y en contra del lugar teológico de las diversas formas familiares, entre los laicos existen distintas miradas acerca del tema; visibilizar estos contrastes, desde la perspectiva de la autora, "podrá facilitar la construcción de diálogos interreligiosos en las familias y la sociedad, incluyendo a los no creyentes que podrían objetar a los rituales, creencias o comunidades religiosas que impregnan cualquier tipo de conformación familiar con alguna significación espiritual" (Mahoney, 2010, p. 813).

En cuanto a la etapa de mantenimiento, la autora señala que "distintas tradiciones de fe están de acuerdo en que los miembros de las familias deben tratarse entre sí de manera que se conserve la calidad y la estabilidad de la relación familiar que ellos crean" (Mahoney, 2010, p. 813). Respecto de las tasas de divorcio, se observa que existe evidencia que una profunda comunidad espiritual en la familia tiende a disminuir el riesgo de divorcio, mientras que una amplia diversidad (familias de fe mixta) puede aumentarlo. Con relación a la satisfacción marital y el compromiso, la autora identifica que hay dispersión en los resultados, lo que sugiere la "necesidad de descubrir los mecanismos espirituales centrados en el matrimonio que importan a ambos esposos" (Mahoney, 2010, p. 814), los cuales no pueden generalizarse, toda vez que se están transformando entre generaciones.

Finalmente, en relación con la transformación de las relaciones familiares en momentos de angustia, la autora señala que "no hay casi investigaciones enfocadas a cómo la religiosidad en general o creencias o comportamientos espirituales específicos pueden operar, para bien o para mal, cuando las crisis familiares tienen lugar" (Mahoney, 2010, p. 818).

\section{Procesos de socialización familiar: Pautas, cre- encias y prácticas de crianza}

Como se enunció en la introducción, la experiencia familiar se concreta en los procesos de socialización familiar, particularmente en lo que a crianza se refiere. Por crianza el equipo investigador, retomando estudios de familias, entiende el

entrenamiento y formación de los niños por los padres o por sustitutos de los padres. También se define como los conocimientos, actitudes y 
creencias que los padres asumen en relación con la salud, la nutrición, la importancia de los ambientes físico y social y las oportunidades de aprendizaje de sus hijos en el hogar (...) La crianza del ser humano constituye la primera historia de amor sobre la que se edifica en gran parte la identidad del niño y se construye el ser social. (Eraso, Bravo y Delgado, citados por Izzedin y Pachajoa, 2009, p. 109)

Se entienden por pautas, "cómo se espera que se comporten los niños y niñas y que están relacionadas con las determinaciones culturales propias del grupo de referencia, y son válidas para un grupo social dependiendo de quién defina lo que es normal o valorado" (Pulido et al. 2013, p. 248), y por extensión, cómo se espera que se comporten las familias en materia religiosa.

Al hablar de creencias, hacemos referencia al "conocimiento básico del modo en que se debe criar a los niños y niñas y es compartido por quienes participan en el proceso de crianza; es decir, son las justificaciones de por qué una práctica es mejor que otra" (Pulido et al., 2013, p. 248), es aquello que se tiene por cierto y que inspira las pautas.

\section{Relaciones entre experiencia religiosa y experiencia familiar}

A partir de la revisión expuesta, se puede reconocer la relación o influencia que ejerce la experiencia religiosa en el modo de configurar la familia. Dicha influencia tiene un vasto horizonte de comprensión que va desde la concepción del carácter sagrado o secular del matrimonio, los fines propios de la familia, la razones de su permanencia o disolución, la presencia o no de hijos; hasta los valores recibidos y transmitidos en familia que predominan bajo la forma de creencias, ritos y pautas de crianza, los roles de género asignados tradicionalmente a hombres y mujeres, la asignación ética de lo correcto o incorrecto de ciertas prácticas, la relación con la autoridad, entre otros (Corpas de Posada, 2006; Mahoney 2010; Aros y Basualto, 2014).
Esta relación, no siempre investigada y teorizada, no es fácil de comprender por la naturaleza misma de estas dos experiencias centrales del sujeto quien es a la vez, un ser familiar (D’Agostino, 2002) y un ser religioso (García-Alandete, 2009). Dicha complejidad es el núcleo mismo de esta relación tanto por la diversidad de las experiencias religiosas y las experiencias familiares, como por razones culturales, religiosas, políticas, entre otras, en la que aquellas se sostienen.

Fruto de las discusiones colectivas del equipo investigador, emergen las siguientes relaciones entre las categorías teóricas: procesos de crianza familiar (creencias, pautas y prácticas) y transmisión de la fe (dimensiones objetiva, simbólica, subjetiva y afectiva de la experiencia religiosa), resaltando siempre que no son definiciones categóricas ni absolutas, sino en construcción permanente por la complejidad de la vida familiar:

- Las creencias (verdades) y las pautas (deber ser) presentes en los procesos de crianza en la vida familiar guardan relación con las dimensiones objetiva y simbólica de la experiencia religiosa, por cuanto estas son transmitidas culturalmente por la comunidad de fe y comunican pautas y normas de comportamiento.

- Las pautas (deber ser) y las prácticas (lo que efectivamente se hace) de crianza, guardan relación con la dimensión subjetiva de la experiencia religiosa, por cuanto la interiorización de la creencia religiosa, define unas normas particulares y se expresa de maneras concretas en la cotidianidad, afines o al margen de la comunidad de fe.

- Finalmente, las prácticas de crianza, además del punto anterior, guardan relación con la dimensión afectiva de la experiencia religiosa, por cuanto a través de ellas la persona se reconoce acogida, amada, o, por el contrario, juzgada y señalada.

\section{Metodología}

Hojas y Hablas No. 20. julio - diciembre de 2020, pp. 97-118 
Una vez concertadas las relaciones entre la experiencia religiosa y la experiencia familiar, se inició la fase de trabajo en campo en la Vicaría Episcopal de Cristo Sacerdote (VETCS). Se mantuvo el ejercicio permanente de reflexividad y diálogo en el equipo investigador $\mathrm{y}$, optando por la triangulación metodológica (Okuda y GómezRestrepo, 2005), se proyectaron dos aproximaciones, una cuantitativa y una cualitativa. Estas dos aproximaciones, en el nivel de los métodos de investigación, trascienden el dualismo epistémico de los enfoques investigativos (cuantitativo y cualitativo, con sus respectivos reduccionismos), y permiten un acercamiento holístico a los fenómenos sociales (en coherencia con la perspectiva sistémico-compleja), gracias al uso de diversas estrategias en su estudio.

Así mismo, teniendo en claro que la población del estudio serían las familias participantes en el segundo semestre de 2018 en procesos de iniciación cristiana (catequesis) de los sacramentos de Eucaristía (primera comunión) y Confirmación en las parroquias de la VETCS, se distinguieron tres estamentos (Cisterna, 2005): niños y niñas (en el caso de la primera comunión), jóvenes (en el caso de confirmación) y padres y madres de familia (en ambos sacramentos), para aproximarse de mejor manera a las experiencias familiares. Posteriormente, emergió un cuarto estamento, catequistas.

Aproximación cuantitativa: Caracterización de la relación de la experiencia religiosa con las pautas y prácticas de crianza en los procesos de transmisión de la fe en familias participantes en catequesis de primera comunión y confirmación en parroquias de la VETCS.

Para esta aproximación la técnica empleada fue la encuesta; el equipo diseñó un cuestionario y su primera versión se socializó con los delegados de pastoral familiar, de iniciación cristiana y el Consejo de arciprestes de la VECTS, instancias desde las que se realizaron comentarios y ajustes al instrumento. Así mismo, el pilotaje de los instrumentos se realizó con los grupos de primera comunión y confirmación de las parroquias Santa María Goretti y Sagrada Eucaristía, de las cuales los dos delegados eran párrocos al momento de la recolección. En la aplicación de pruebas piloto el cuestionario recibió retroalimentación por parte de padres y madres de familia, niños y niñas de primera comunión y jóvenes de confirmación, lo que permitió el diseño final del cuestionario. Inicialmente, se habían previsto preguntas cerradas de única respuesta, sin embargo, la prueba piloto permitió validar las opciones y seleccionar las preguntas que requerían múltiple respuesta.

Teniendo en cuenta las relaciones emergentes que se enunciaron en el apartado anterior, el equipo diseñó un cuestionario que permitiera indagar información en torno a las creencias, pautas y prácticas de crianza que se dan en las familias en los procesos de transmisión de la fe. Para ello, se escogieron seis temas que hacen parte de la formación en la fe y de los procesos de catequesis de iniciación cristiana: Dios, religión, iglesia, fe, perdón, oración. Sobre cada tema se formularon tres preguntas orientadas a identificar creencias (verdades), pautas (deber ser) y prácticas (lo que efectivamente se hace). Cada pregunta tenía opciones de respuesta que permitirían aproximarse a las distintas dimensiones de la experiencia religiosa. Todas las preguntas fueron cerradas de opción múltiple, once con única respuesta y nueve con múltiple respuesta. El planteamiento de las preguntas se adaptó en su lenguaje según las características de los grupos poblacionales participantes, obteniendo así tres modelos del cuestionario: uno para niños y niñas de primera comunión, uno para jóvenes de confirmación y uno para madres y padres de familia.

En los modelos dirigidos a jóvenes de confirmación y a madres y padres de familia se incluyó una última pregunta orientada a indagar la relación entre fe y vida cotidiana, abordando cinco temas previamente escogidos por el equipo investigador: división de las labores en el hogar, 
comprensión de los roles de género, vida política, expresión de afecto y comprensión del papel de las distintas instituciones sociales, que debían valorarse en una escala de Likert de cinco opciones: influye totalmente, bastante pero no totalmente, algunas veces, poco, nada.

En la siguiente tabla se sintetiza la distribución de preguntas:

Para la aproximación cuantitativa la muestra fue no probabilística, se propuso realizar un muestreo aleatorio simple por conglomerados, donde cada conglomerado correspondía a un arciprestazgo de

\begin{tabular}{|c|c|c|}
\hline Tema & Tipo de pregunta & Número de preguntas \\
\hline \multicolumn{2}{|c|}{ Preguntas sociodemográficas } & 5 \\
\hline \multirow[t]{2}{*}{ Dios } & Unica respuesta & 2 \\
\hline & Múltiple respuesta & 1 \\
\hline \multirow[t]{2}{*}{ Religión } & Única respuesta & 4 \\
\hline & Múltiple respuesta & 1 \\
\hline \multirow[t]{2}{*}{ Perdón } & Única respuesta & 3 \\
\hline & Múltiple respuesta & 0 \\
\hline \multirow[t]{2}{*}{$\mathrm{Fe}$} & Única respuesta & 2 \\
\hline & Múltiple respuesta & 1 \\
\hline \multirow[t]{2}{*}{ Iglesia } & Única respuesta & 0 \\
\hline & Múltiple respuesta & 3 \\
\hline \multirow[t]{2}{*}{ Oración } & Única respuesta & 0 \\
\hline & Múltiple respuesta & 3 \\
\hline $\begin{array}{l}\text { Fe y vida cotidiana } \\
5 \text { tópicos }\end{array}$ & Lickert & $\begin{array}{c}1 \\
\text { Únicamente en modelos para confirmación y padres madres de familia }\end{array}$ \\
\hline
\end{tabular}

Tabla 1. Distribución de preguntas por tema en las encuestas

VETCS, para un total de siete, y de cada uno vincular 3 parroquias que estuvieran desarrollando procesos de catequesis en el segundo semestre de 2018. En cada parroquia se contó con dos unidades de análisis: las familias participantes en catequesis de primera comunión, y las familias participantes en catequesis de confirmación.

Se realizaron en total 857 encuestas, de las cuales 424 correspondían a padres y madres de familia, 55 a jóvenes de confirmación y 378 a niños y niñas de primera comunión, distribuidos en 18 parroquias de la VETCS entre agosto y octubre de 2018. Vale la pena precisar que la recolección de información se llevó a cabo entre finales de septiembre a finales de noviembre de 2018, y la mayoría de las parroquias estaban terminando sus procesos de catequesis, por lo que se destaca la apertura y acogida de párrocos, equipos de catequistas y familiares en la participación.
Aproximación cualitativa: Una vez tabulada la información cuantitativa e identificados sus resultados, y en sintonía con la triangulación metodológica, se realizó un taller con catequistas, donde, a través de grupos focales se buscó profundizar en los resultados obtenidos y, así, profundizar en las categorías emergentes. Esta etapa se llevó a cabo el primer semestre de 2019.

Es importante destacar que en este momento de la investigación emergen los catequistas como actores fundamentales con gran experiencia en el trabajo con familias, y un rol protagónico en las pautas y prácticas que estas configuran en los procesos de transmisión de la fe. El equipo investigador consideró, entonces, la preparación de grupos focales a partir de algunos datos de la primera fase y preguntas guía para la conversación. Se elaboraron preguntas alrededor de aspectos relacionados con la composición familiar, sus cambi- 
os y desafíos contemporáneos; las creencias familiares y las creencias alrededor de la figura de Dios, y los procesos de enseñanza y transmisión de la fe.

Los grupos focales se aplicaron en el marco del encuentro vicarial de catequistas correspondiente a la Vicaría Episcopal Territorial Cristo Sacerdote realizado el sábado 13 de abril de 2019 en las instalaciones de la vicaría en mención. Dicho encuentro contó con asistencia de 20 catequistas, que participaron en el desarrollo de los grupos focales. Se conformaron 4 grupos de 5 catequistas cada uno, en cada grupo había participación de dos miembros del equipo investigador, quienes propusieron las preguntas orientadoras definidas previamente y animaron el diálogo.

\section{Resultados y discusión}

El 56\% de los acudientes participantes corresponde a las madres de las personas participantes en Catequesis, seguido del $20 \%$ correspondiente a padre y madre. La proporción de madres contrasta con el $12 \%$ de padres que respondieron la encuesta. En todos los arciprestazgos se conserva esta tendencia, sin embargo, se puede resaltar que donde se tuvo mayor participación de padres y madres fue en la parroquia de la Calera, alcanzando cerca de la mitad del total de madres participantes. De aquí se podría intuir que la formación en la fe, o por lo menos la representación ante la institución eclesial, es una función familiar que se asigna de forma predominante a la mujer.

Como se observa en la Figura 1, con relación al estado civil de los padres y madres de familia el 28\% que afirman estar casados, mientras que el 68\% expresaron situaciones que permiten pensar en distintas

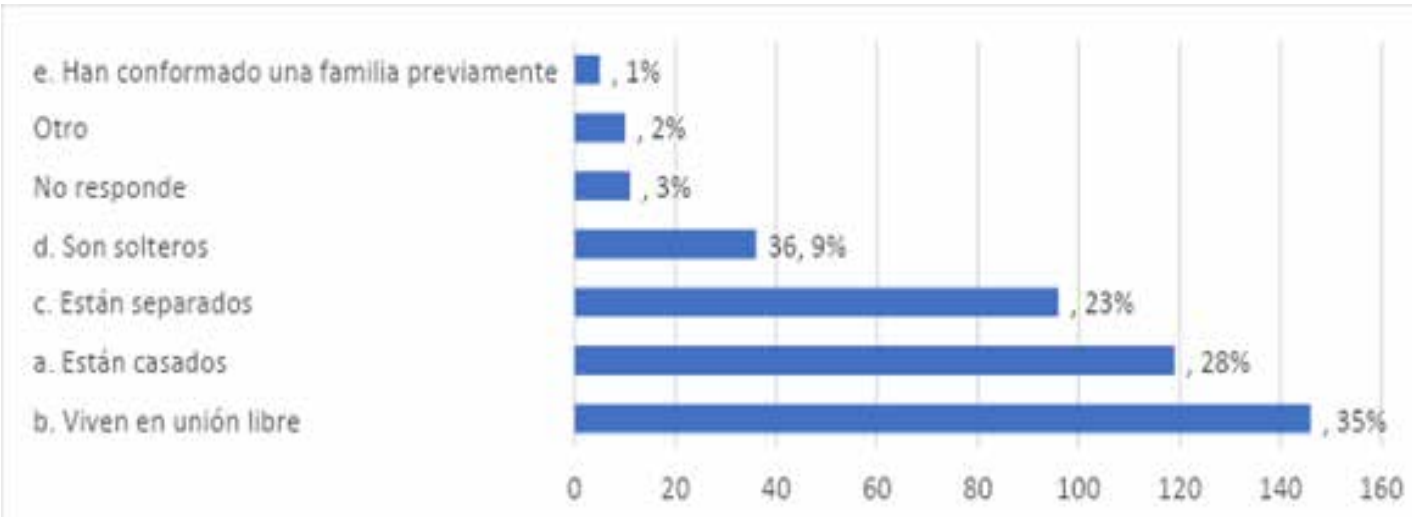

Figura 1. Estado civil padres y madres de familia

conformaciones familiares (unión libre, recomposición familiar, separación, soltería) participando en los procesos de formación en la fe, lo cual propone un diálogo necesario entre estas dos realidades, de lo que surgen algunas preguntas; ¿cómo se comprende la fe en esta diversidad?, ¿cómo se dialoga con estas conformaciones familiares en los procesos de catequesis?, ¿se puede correr el riesgo en propiciar un doble mensaje en la formación de la fe en los niños y niñas?
Respecto de la postura religiosa, el $77 \%$ de los padres y madres profesan la fe católica, un $10 \%$ donde si bien ambos son católicos uno no lo practica, y un 3\% donde se profesan distintos tipos de creencias. De estos porcentajes menores, cerca del $70 \%$ de las respuestas corresponde con las mamás de los participantes, lo que permitiría reforzar la función religiosa en perspectiva de género. 
Así mismo, se realizó la caracterización de la experiencia religiosa a la luz de los seis ejes temáticos identificados en las encuestas. Sin embargo, por efectos de la extensión del presente artículo se reportan los resultados relacionados con los grupos focales realizados con los catequistas.

Respecto de la comprensión de Dios, expuesta en las Figuras 2, 3 y 4 la respuesta predominante de los padres y madres tiene relación con la afirmación doctrinal sobre Dios desde el catolicismo: Padre creador; mientras que en niños, niñas y jóvenes se involucran aspectos de orden afectivo, al relacionarlos
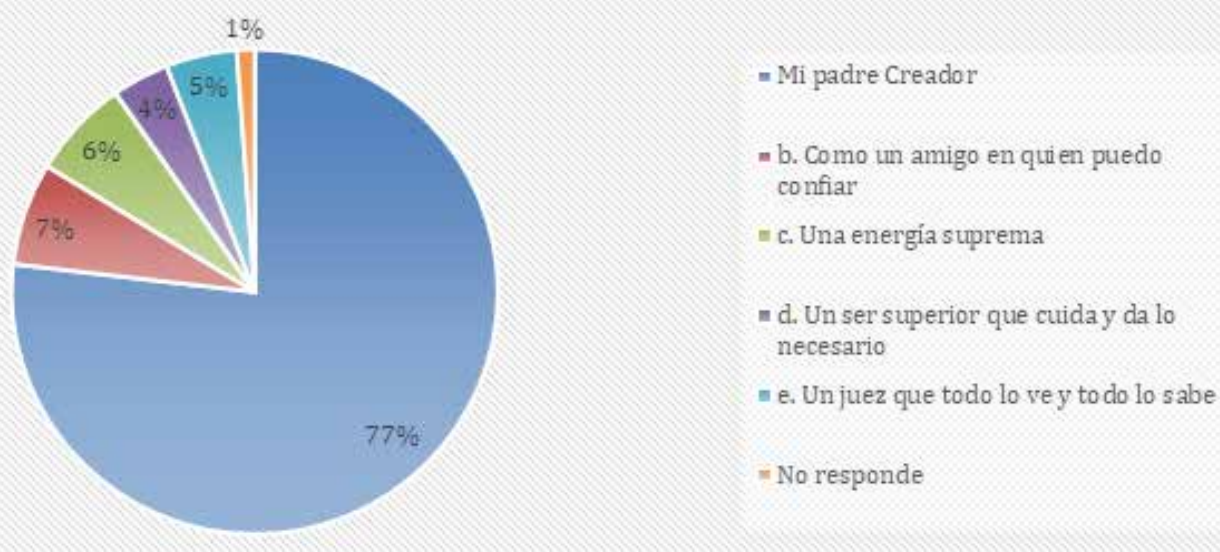

Figura 2 ¿Quién es Dios para ti? Padres y madres de familia (Fuente: Encuestas - Modelo P\&M)

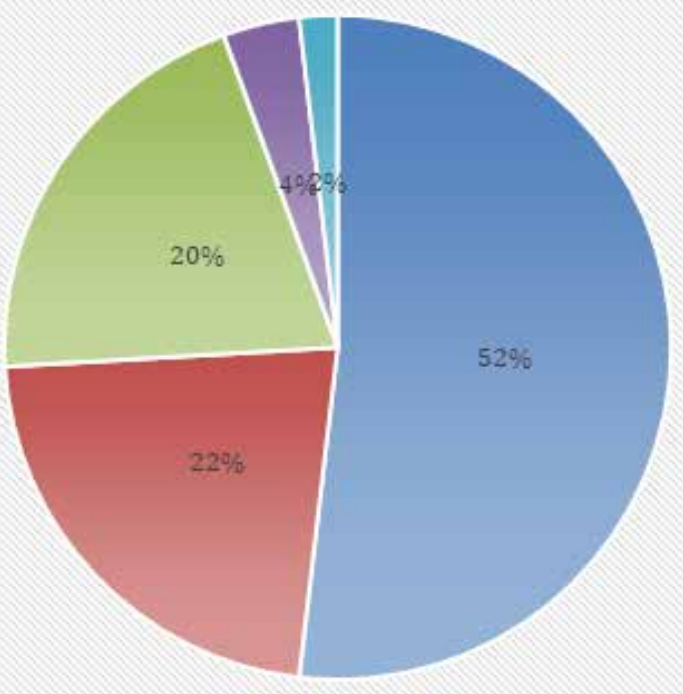

n b. Como un amigo en quien puedo confiar

- a. Un ser como mi papá o mi mamá

n c. Una energía suprema.

- e. Algui en que me juzga y ve todo lo que hago

" a. Un ser como mi papá o mi mamá, b. Como un amigo en quien puedo confiar

Figura 3. ¿Quién es Dios para ti? - Confirmación (Fuente: Encuestas . Modelo CONF) 


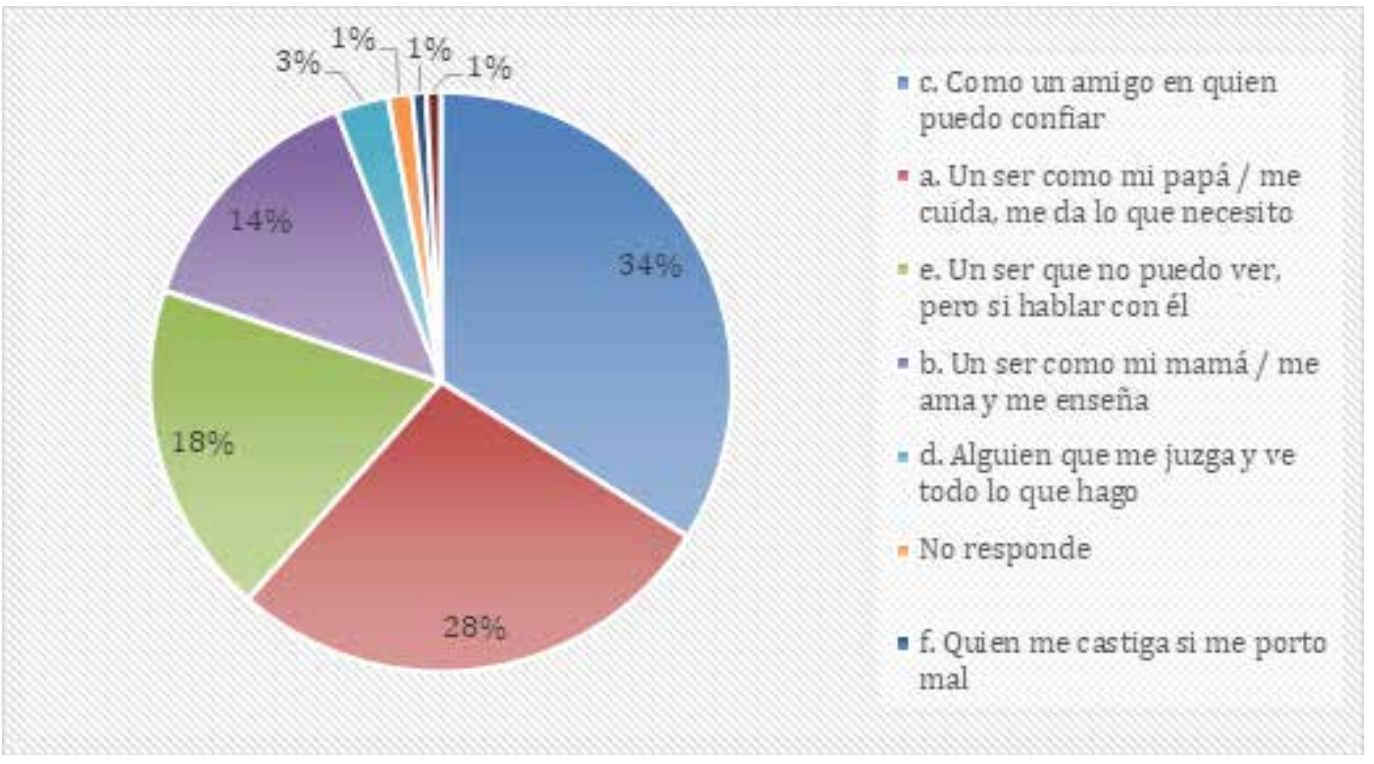

Figura 4. ¿Quién es para ti? Primera Comunión (Fuente Encuestas - Modelo PC)

con un amigo en quien se puede confiar o actitudes paternales y maternales, como la protección, el cuidado y el amor.

En ellas y ellos las respuestas pueden tener relación con las vivencias propias de la etapa vital en la que se encuentran. En jóvenes de confirmación la respuesta predominante señala la comprensión de Dios como amigo en quien se puede confiar (52\%) y el $22 \%$ hace referencia a los padres; por su parte en niños y niñas, si bien la mayoría señala la comprensión como amigo (32\%), no es predominante, $\mathrm{y}$ se presentan alusiones a las figuras paternas: al padre que cuida y protege $(28 \%)$ y la madre que ama y enseña (14\%), lo cual se puede relacionar también con la afirmación doctrinal involucrando aspectos afectivos.

Es importante observar que, el $20 \%$ de los jóvenes señaló a Dios como una energía suprema, y el $18 \%$ de los niños y niñas como un ser que no se puede ver, pero con el que se puede hablar. Estas respuestas, pueden constituir indicios de configuraciones de la experiencia religiosa de carácter subjetivo, al margen de los contenidos doctrinales, sin olvidar que los participantes se encuentran en un contexto de catequesis de iniciación cristiana.

Al preguntar por lo que se enseña en la familia sobre Dios (esto es, pautas de crianza), se presenta correspondencia entre creencias y pautas entre cada estamento: en los padres y madres, en ambos grupos, predomina la enseñanza de Dios como creador de cuanto existe, seguido de un ser bueno y protector; las demás opciones de respuesta ofrecidas no presentan tendencias que llamen la atención. Por su parte, entre jóvenes, niños y niñas predomina la respuesta de ser bueno y protector, y se presentan los matices indicados al abordar las creencias: en jóvenes el 76\% afirma que le enseñan que es un ser bueno y protector, y el $20 \%$ que es creador; mientras que en niños y niñas el $60 \%$ hace referencia a la primera respuesta y el $37 \%$ a la segunda.

\section{Discusión de resultados con catequistas Reflexiones sobre la conformación familiar}

El primer punto de conversación se deriva de los resultados derivados del estado civil de los padres y madres de familia. A partir de la conver- 
sación, se pueden ubicar en varias tendencias:

a) Crisis de valores y falta de compromiso en las familias. Para algunos de los participantes consultados, la familia como institución tradicional se encuentra en crisis y asocian los cambios en su configuración a un proceso de pérdida de valores en la sociedad. Es posible ubicar en esta tendencia a los participantes que consideran que la fe católica se encuentra cada vez más dispersa en las familias, puesto que los procesos de enseñanza y transmisión de la fe no alcanzan a responder a los cambios sociales y culturales que se están viviendo. Estos participantes incluso consideran que estos cambios en la configuración de las familias se deben a la declaración de Colombia como Estado laico en la Constitución Política de 1991. En esta tendencia se ubican además quienes consideran que las familias se preocupan porque sus hijos hagan parte de los procesos de catequesis, sin que padres y madres manifiesten interés por participar en el matrimonio y siguen viviendo en unión libre o bajo otras modalidades.

b) Poca innovación de la iglesia en los procesos de catequesis. Algunos de los catequistas consultados muestran una postura más reflexiva con respecto las herramientas en las que se apoya la Iglesia Católica para convocar y desarrollar procesos de catequesis; en este grupo es posible ubicar a quienes consideran que los procesos de formación y transmisión de la fe se quedaron en las normas establecidas sin tener en cuenta las nuevas configuraciones familiares. Para estos participantes es responsabilidad de la iglesia desarrollar nuevas formas para acercar a las familias. En esta porción también es posible ubicar a quienes con respecto al 30\% de padres separados consideran que esto se debe a la concepción 'desechable' del matrimonio, puesto que desde su perspectiva ahora hay cursos rápidos de preparación para el matrimonio y no hay espacios de acompañamiento para que la pareja siga trabajando en su unión a través de la fe católica. c) Necesidad de procesos de transformación y procesos de fe que involucren a la familia. En un tercer grupo de tendencia se pueden ubicar quienes consideran que es fundamental que la Iglesia desarrolle procesos de formación y acompañamiento en los que se trabaje la enseñanza y la transformación de la fe. En esta medida, la catequesis debe ser considerada como un proceso continuo y no solo como una ceremonia o rito puntual, por lo que las y los catequistas consultados consideran que es importante trabajar y formar a las familias y no solo a los niños y a los jóvenes. Se preguntan cómo la Iglesia podría desarrollar procesos que tengan como propósito 'catequizar a la familia'.

\section{Reflexiones acerca de la postura religiosa de las familias}

a) Poca coherencia en las familias. Desde la perspectiva de esta tendencia, el que existan familias en las que coexistan distintas creencias genera confusión en los niños, niñas y jóvenes con respecto a cuál debe ser su creencia puesto que las familias deben dar testimonio y coherencia de vida; si el padre y la madre transmiten creencias distintas los hijos no tienen una guía clara sobre qué posición tomar; situación que a la larga termina debilitando a las familias.

b) El acercamiento de familias con otras creencias es una oportunidad para la Iglesia católica. Para otra porción de los y las catequistas consultados los procesos de catequesis deben estar dirigidos a familias más que a individuos sin importar la configuración de estas familias o la confluencia de creencias que en ellas tengan. En el marco de estos relatos es posible destacar que si bien los niños de padres con distintas creencias asisten porque sus tíos o abuelos los llevan; o porque uno de los padres insiste en hacerlo; esto no debe ser considerado una desventaja o un problema para la Iglesia católica, por el contrario debería pensarse como una oportunidad para acercar a personas que profesan otras creencias puesto que algunos 
padres o familiares al ver el proceso de sus hijos quieren vincularse a la religión católica. Algunos de los que ven esta situación como oportunidad consideran que, ante un mundo distinto, con familias distintas, "el discurso debe adecuarse ya que es diferente para los niños, los jóvenes o los padres. Ahora estamos viviendo un mundo distinto por lo tanto el discurso tiene que cambiar" (grupo focal 13 de abril 2018).

Finalmente, y en el marco de esta pregunta, para algunos de los catequistas consultados también es importante preguntarse y reflexionar acerca de ese $10 \%$ que afirma ser católico no practicante, ¿a qué se refiere esto? Es necesario conversar con las familias acerca de este tema; pues no es claro cómo es para ellas autoreferenciarse como miembros de la iglesia católica, pero con la salvedad de ser 'no practicante'.

\section{Reflexiones en torno a las concepciones acerca de Dios}

a) Los 'riesgos' de ver a Dios como amigo. Para algunos de las y los catequistas que participaron en los grupos focales ver a Dios como un amigo puede ser un 'arma de doble filo', puesto que puede ser percibido como 'el parcero' (sic) y el que todo lo perdona. Desde su perspectiva, esto puede distorsionar la imagen de Dios y no se puede asemejar a Dios con cualquier cosa puesto que creer en Él también exige responsabilidades y comportamientos según unos valores establecidos y compartidos por la comunidad católica. Dios tiene un carácter especial al ser el creador y salvador; hay mucha confusión hoy en día, entonces Dios se diluye en la nueva era con concepciones como 'el universo' o el 'cosmos' y pierde en las creencias de las familias lo que lo hace ser único y todopoderoso.

b) Presentar a Dios como amigo como estrategia de acercamiento. Desde la perspectiva de otros catequistas, presentar a Dios como amigo puede representar "una experiencia bonita de acercamiento a Dios" (grupo focal 13 de abril 2018); mostrar a Dios como amigo hace parte de las nuevas formas de catequizar, mostrarlo más humano, y más cercano es una forma de acercar a las nuevas generaciones. También hay que tener en cuenta que en la actualidad los jóvenes son más racionales y cuestionadores, tienen acceso a todo tipo tecnologías e información y les cuesta creer en Dios, por lo tanto, hay que desarrollar nuevas estrategias de acercamiento hacia ellos. Ver a Dios como un amigo puede representar el percibirlo como el ser en el que puedo confiar, además una relación de amistad también implica responsabilidades y desarrollar una relación personal con Dios.

\section{Reflexiones en torno a la experiencia de fe en las familias.}

Las opiniones se orientan a considerar que padres y madres no tienen suficiente conocimiento y compromiso con los procesos de catequesis. Ellos y ellas suelen trasladar la responsabilidad en la enseñanza y transmisión de la fe a los catequistas o a otros familiares, aunque la catequesis también es responsabilidad de la familia, en especial de los progenitores. Consideran además que los padres y madres no tienen suficientes elementos para dar respuesta a sus hijos

Yo agregaría: cómo podemos hablar de Dios si no leemos las escrituras, la palabra, ahí es donde conocemos quién es Dios, entonces, nos cerramos a que en una reunión ya vimos todo eso, pero si no hay una vivencia de la palabra de Dios no se puede hablar de quién es Dios. (grupo focal 13 de abril 2018)

En las prácticas de crianza de las familias hay tradición, pero no hay suficiente convicción, tampoco procesos de formación que les permitan a los padres transmitir la fe a sus hijos de forma adecuada. Por tanto, es importante trabajar desde el compromiso y la responsabilidad conjunta y no desde la obligación; las catequesis deben ser procesos formativos y no solo coyunturales, en los que los catequistas tengan la posibilidad de hacer mayor seguimiento a las familias. 


\section{Reflexiones en torno a la relación procesos de} catequesis - cambios de las dinámicas familiares

Se identifican las siguientes tendencias:

a) Las dificultades de los cambios en la familia. Algunos de los catequistas consultados consideran que las familias han perdido autoridad, y esto ha incidido negativamente en las representaciones y prácticas alrededor de la crianza. Cada vez es más difícil corregir a los niños, niñas y jóvenes, puesto que "ya no se les puede decir nada" (grupo focal 13 de abril 2018); en este grupo se ubican quienes además consideran que hay mucha permisividad y mal uso de las herramientas tecnológicas, lo cual dificulta realizar con ellos las actividades que están previstas en el proceso de catequesis.

b). Cambios en los procesos de catequesis. Algunos de los participantes consultados consideran que los procesos de catequesis han tenido en cuenta las transformaciones de las familias al enseñar y transmitir la fe a través del juego y se apoyan cada vez más en herramientas lúdicas. Los participantes consideran que los procesos pastorales tratan de ser cada vez más animados y participativos, y que se realizan actividades recreativas dirigidas a niños y niñas para que sus padres no tengan excusas para no asistir. Consideran que la Iglesia Católica ha hecho cambios y que, por ejemplo, tiene canciones de todos los géneros musicales para acercar a personas de distintas edades.

Finalmente, insisten en la necesidad de fomentar la inclusión de padres y madres en el proceso de catequesis; teniendo en cuenta las distintas culturas y el contexto socioeconómico del que estos provienen. Sugieren además conocer las realidades de los grupos de padres, jóvenes y niños para enfocar el camino de la fe. Insistieron, además, en la necesidad de realizar procesos de formación con padres de familia y promover que ellos también lideren procesos de enseñanza y transmisión de la fe.

\section{Conclusiones}

El ejercicio investigativo expuesto en el documento da cuenta de la importancia de seguir promoviendo la sinergia dinámica entre la academia y la pastoral en las distintas instituciones de la Arquidiócesis de Bogotá, particularmente, entre las parroquias y la Unimonserrate. Estos puentes son necesarios toda vez que la dimensión religiosa es parte constitutiva de los procesos culturales y políticos en los que viven inmersas las comunidades, y es papel de la academia develarlos, comprenderlos y contemplarlos al momento de pensar las estrategias de acción tanto profesional como pastoral, toda vez que "las líneas de una investigación son trazadas por las temáticas de cada contexto educativo, por los diferentes factores sociales, culturales, políticos, económicos, religiosos y académicos que se encuentran dentro o fuera de las universidades" (Flórez et al., 2019, p. 39).

Además de dar cuenta de un conjunto de percepciones acerca de los procesos de catequesis de iniciación cristiana en la población interveni$\mathrm{da}$, el equipo investigador propone algunas pautas para la reflexión como una "devolución creativa" (Flórez et al., 2019), como "etapa fundamentalmente prospectiva que debe responder a la pregunta: ¿Qué aprendemos de lo que hacemos?” (p. 44). En este sentido, si bien prima el lenguaje pastoral, y la aplicabilidad de los resultados en procesos de catequesis concretos, estas conclusiones tienen su fundamento en el ejercicio investigativo dialógico expuesto.

$\mathrm{Al}$ abordar la relación entre las experiencias religiosas y los procesos de crianza en las familias, se constata la complejidad del fenómeno religioso, incluso en quienes identificándose como católicos incorporan a su fe creencias y prácticas no relacionadas directamente con la fe en mención. Esto es un signo del cambio cultural y religioso que experimenta la sociedad contemporánea (Aznar, 
2020) y que pastoralmente demanda ser visto como oportunidad de revisión de ciertas prácticas evangelizadoras, pues interpela a la Iglesia en su capacidad de conocer los rostros concretos del entorno, dialogar con la diferencia, salir al encuentro del otro en su dignidad y riqueza. Precisamente, Merino (2010) afirma que:

el reconocimiento de la diversidad religiosa latinoamericana no ha sido un camino fácil para la teología católica. Más bien ha sido un proceso largo al que le han ayudado los aportes de diversas ciencias humanas y sociales, y que ha requerido una mirada cualitativa de nuestra realidad y la valoración de las minorías en su riqueza cultural y religiosa (p. 59).

Esta complejidad propone el reto, tanto a la academia como a la pastoral de no solo hacer alusión enfática a lo faltante, sino de valorar lo emergente: los nuevos modos de relacionarse con Dios, de expresar la fe y de comunicarla. La diversidad constituye una oportunidad para interpretar y profundizar en la valiosa categoría teológica de los signos de los tiempos, los diversos modos como Dios sigue estando presente en la historia (Gaudium et Spes,11) evitando encerrarse en el miedo o la impotencia que pareciera frenar la riqueza del diálogo fe-Mundo, tal como lo señala el V documento de la Conferencia Episcopal Latinoamericana de Aparecida hablando de la pastoral urbana (DA, 513).

Por otra parte, los diversos modos de vivir la fe y de expresarla, particularmente en los procesos de transmisión de la fe en las nuevas generaciones en un ámbito secularizado y posmoderno (Aznar, 2019) requiere de un ejercicio de diálogo intergeneracional y de apertura que posibilite la acogida del otro reconociéndolo en su dignidad y en la particularidad de su experiencia religiosa, promoviendo así una cultura del encuentro y del respeto (Arquidiócesis de Bogotá, 2017). Es urgente salir de una "pastoral de conservación" de "gestión de prácticas religiosas"; "de metodologías tradicionales" para tener el valor de ocupar otros espacios "más allá de los tradicionalmente sagrados" teniendo en cuenta la circunstancias propias del contexto y las "territorialidades" de la cultura urbana (Salazar, 2012; Arquidiócesis de Bogotá, 2013).

En segundo lugar, al abordar en este estudio la complejidad de la experiencia religiosa desde las cuatro dimensiones (objetiva, simbólica, subjetiva y afectiva), se puede concluir la importancia de recuperar, en las búsquedas de sentido personales, un lugar de encuentro para el diálogo religioso y cultural. Este pluralismo constituye una oportunidad para visibilizar los diferentes modos como, en la actualidad, el sujeto desea, busca y se comunica con la trascendencia, siempre mediado por una experiencia personal que en no pocas ocasiones está al margen de las instituciones religiosas y su normatividad. En este punto, la falta del encuentro personal con Jesucristo como problema focal de la evangelización (Arquidiócesis de Bogotá, 2013), no puede superarse si se sigue suponiendo la presencia de la fe en los fieles; y si se enfatiza en sostener prácticas religiosas de carácter meramente 'ritualista' (Arquidiócesis de Bogotá, 2012) sin espacios que permitan narrar las experiencias de fe, particularmente al interior de las prácticas de trasmisión de la fe de padres a hijos y los procesos catequéticos de iniciación cristiana.

Sobre esta dinámica de la fe, entendida como aprendizaje de contenidos y encuentro personal con Dios (Benedicto XVI, 2005), se están abriendo nuevos caminos en los procesos de primer anuncio y de la iniciación cristiana desde una clave 'narrativa' que permite al sujeto expresar, comunicar, interiorizar la fe. La catequesis misma debe continuar apuntando a crear espacios de diálogo y aprehensión de la fe, donde el sujeto es protagonista, guiado por la fuerza de la palabra de Dios, acompañado por la comunidad creyente y puesto en un itinerario donde los tiempos de desarrollo y opción de la fe no vienen marcados desde fuera, o en función de un programa por cumplir, sino que marchan al ritmo de cada creyente y su experiencia personal con Cristo. En el estudio presen- 
tado, por ejemplo, la comprensión de Dios como un amigo refleja esta necesidad de encontrarse con Dios, narrar la fe y comunicarse con lo divino desde otro ángulo, marcadamente relacional.

En tercer lugar, el reconocimiento de las distintas maneras como se conforman las familias que participan en los procesos de formación cristiana, que no siempre coincide con la relación entre familia y sacramento del matrimonio, invita a dialogar entre las experiencias de catequesis (en este caso particular) y las realidades familiares (diversas y no una sola realidad) en los procesos de evangelización. En el ejercicio del grupo focal con los catequistas emergió que, al no conocer de manera individual estas diferencias familiares en los procesos de iniciación cristiana de niños y jóvenes, se generaliza el discurso sin entrar en contacto directo con las familias, desconociendo sus procesos y problemáticas, sus preguntas y demandas en el campo de la evangelización.

El tema de las diversas configuraciones familiares constituye un escenario de diálogo valioso entre la academia y pastoral para reconocerlas, conocerlas y acompañarlas en el proceso evangelizador. La mencionada 'crisis de fe en las familias' puede expresar, en muchos casos, temores, dudas, dolores y desesperanzas, a los cuales también la Iglesia, pastoralmente, deber salir al encuentro, acompañándolas de manera cercana, diferenciada y gradual (Juan Pablo II, 1981; Francisco, 2016), y para ello los desarrollos de las ciencias sociales y los estudios de familia puede constituir un insumo importante, teniendo presente la diversidad de perspectivas desde los que se abordan.

Finalmente, este ejercicio de diálogo con los catequistas, las familias, pero también con los equipos de la VETCS, lleva a reconocer el valor de la catequesis, no sólo en la labor evangelizadora (que es fundamental), sino, también, como proceso educativo que hace parte de la función socializadora de las familias, retomando el valor teológico y sociológico de la categoría de Iglesia doméstica. El diálogo familia-catequesis, que en el campo educativo permite pensar en el diálogo familia-escuela, se hace necesario para revisar los criterios que inspiran su configuración, teniendo en cuenta el aporte que se puede brindar desde distintos modelos pedagógicos y sus desarrollos contemporáneos: el valor del diálogo de saberes que permite el intercambio de experiencias situándose en horizontes liberadores de la persona (evocando a Freire), la centralidad en el estudiante que otorga un papel activo al catequizando (evocando las recientes comprensiones alternativas a la escuela tradicional o educación bancaria), y la comprensión de los distintos actores como aprendientes permanentes (desde los abordajes de la complejidad y la sistémica), lo que implica la revisión constante de los procesos de catequesis en las parroquias y su innovación año tras año.

No se puede negar que las catequesis reflejan los modelos educativos de los que las sociedades son herederos, por esta razón se hace cada vez más urgente: a) habitar los espacios virtuales y evangelizar desde las nuevas herramientas tecnológicas (como lo demandó inexcusablemente la pandemia); b) promover espacios de desarrollo de habilidades blandas en los catequistas, particularmente la capacidad de escucha, acogida a la interpelación y en la manera como se presenta el mensaje religioso, que pese a los esfuerzos de renovación sigue siendo especulativo; c) contrarrestar la escolarización de la catequesis, expresada en la preocupación de tener respuestas hechas o programas definidos que se deben desarrollar, incluso al margen del proceso vivido por el sujeto creyente; d) integrar sinérgicamente parroquia, comunidad y familia como ambientes insustituibles del hecho religioso y la vivencia de la fe.

Lo anterior refleja el valor del desarrollo de ejercicios interdisciplinares, en la profundidad de esta palabra, donde las verdades que se construyen en cada orilla de las disciplinas no constituyen el punto de partida de la experiencia investigativa, sino parte de los insumos que se traen a lugar y se 
reconstruyen, más que para cambiar la doctrina, sobre todo para resignificar la vida, reconociendo en ella los procesos donde acontecen los aprendizajes y la salvación.

\section{Referencias bibliográficas}

Arocena, F. M. (2011). El lenguaje simbólico de la liturgia, Scripta Theologica,Vol 43, 103124. Recuperado de https://revistas.unav. edu/index.php/scripta-theologica/article/ view/3297

Aros Vega, J. y Basualto Porra, L. (2014) Aportes a la teología de la familia. Lectura eclesiológica de la Iglesia doméstica, Veritas, (30), 163-186. https://dx.doi.org/10.4067/S071892732014000100008

Arquidiócesis de Bogotá. Vicaría de Evangelización (2013). Plan de Evangelización 20132022. Bogotá - Colombia: Instituto San Pablo Apóstol (ISPA). Recuperado de: https:// issuu.com/voxstudio/docs/plane

Arquidiócesis de Bogotá. (2017). Hoy salimos testigos de la Misericordia 2016-2019, Plan de Evangelización, Nuevo Rumbo, Documento No 7, Segunda Etapa. Bogotá- Colombia: Editorial Carrera 7 S.A.S. Recuperado de: http://plane.arquibogota.org.co/ es/noticias/10856-documento-no-7-nuevorumbo-hoy-salimos-testigos-de-la-misericordia.html

Aznar Sala, J. (2019), La familia ante la transmisión de la fe en un contexto de secularización. Familia. Revista de Ciencias y Orientación familiar, (57), 29-53. Recuperado de https:// summa.upsa.es/viewer.vm?id=107837

Aznar Sala, J, (2020). La familia como germen de un nuevo impulso evangelizador. Familia. Revista de Ciencias y Orientación familiar, (58), 41 - 64. Recuperado de https://summa. upsa.es/viewer.vm?id=131282

Benedicto XVI (2005), Carta Encíclica Deus Caritas Est. Recuperado de http://www.vatican. $\mathrm{va} /$ content/benedict-xvi/es/encyclicals/ documents/hf_ben-xvi_enc_20051225_de- us-caritas-est.html

Borobio, D. (2003). Celebrar para vivir, liturgia y sacramentos de la Iglesia. Salamanca: Sígueme.

Borobio. D. (2000). Ritos en Familia y transmisión. Familia. Revista de Ciencias y Orientación familiar (22), 11 - 6. Recuperado de https://summa.upsa.es/pdf.vm?id=0000028 318\&page $=1$ \&search $=$ \&lang $=\mathrm{es}$

Cisterna Cabrera, F. (2005). Categorización y triangulación como procesos de validación del conocimiento en investigación cualitativa. Theoria, Col. 14 (1), 61-71. https://www.redalyc.org/pdf/299/29900107.pdf

Conferencia del Episcopado General Latinoamericano y del Caribe (2007). Documento de Aparecida (DA). Recuperado de https:// www.celam.org/aparecida/Espanol.pdf

Corpas de Posada, I. (2010). Experiencia religiosa y lenguaje religioso: aproximación teológica. Franciscanum. Revista de las ciencias del Espíritu, Vol. LII, (153), 57-95. https://doi. org/10.21500/01201468.934

Corpas de Posada, I. (2006). La familia, experiencia humana y sacramento de salvación. Apuntes para una teología de la familia. Theologica Xaveriana (159), 425-442. Recuperado de http://www.redalyc.org/ pdf/1910/191017475003.pdf

D’Agostino, F. (2002), Elementos para una filosofía de la familia. Instituto de ciencias para la familia, Madrid-España: Ediciones Rial 2a

Dorronsoro, R. D. (2014). La noción rahneriana de símbolo esencial revisada a partir de la antropología trascendental de Leonardo Polo. Miscelánea Poliana, Vol. 46, 1-41. Recuperado de http://www.leonardopolo.net/ revista/mp46.htm

Flórez Valencia, G. A., Santamaría Rodríguez, J. E., Barreto Salamanca, N. y Álvarez Cruz. E. Y. (2019). Tendencias de investigación educativa. Concepciones y oportunidades. Colección Cuadernillos de Investigación Serie 4 educación, Cuadernillo 4. Corporación Universitaria Minuto de Dios - 
UNIMINUTO: Bogotá -Colombia. Recuperado de: https://www.researchgate.net/ publication/342845408_Tendencias_en_investigacion_educativa_Contextos_y_oportunidades

Francisco (2016). Exhortación Apostólica Postsinodal Amoris Laetitia. Recuperado de http://www.vatican.va/content/francesco/ es/apost_exhortations/documents/papafrancesco_esortazione-ap_20160319_amoris-laetitia.html

Gallego, M. (2010). Claves de la experiencia religiosa en Aparecida: Un aporte para la Pastoral juvenil. Alteridad, 39-46. Recuperado de https://dialnet.unirioja.es/descarga/articulo/5981123.pdf

García-Alandete, J. (2009). Sobre la Experiencia religiosa: aproximación fenomenológica. Folios, Segunda época, (30), 115-126. Recuperado de http://www.scielo.org.co/pdf/ folios/n30/n30a08.pdf

Guardini, R. (1964). Religión y Revelación. Cristianismo y hombre actual 24, 2a Edición, Madrid-España: Ediciones Guadarrama, S.L.

Guardini, R. (1997). La Existencia del Cristiano. Madrid-España: Biblioteca de Autores Cristianos

Guardini, R. (2016). Experiencia religiosa y fe. Estudios y Ensayos. Madrid-España: Biblioteca de Autores Cristianos

Izzedin, R., y Pachajoa, A. (2009). Pautas, prácticas y creencias acerca de crianza... Ayer y hoy. Liberabit, 15 (2), 109-115. Recuperado de http://www.scielo.org.pe/pdf/liber/v15n2/ a05v15n2.pdf

Juan Pablo II (1981). Exhortación Apostólica Familiaris Consortio. Recuperado de http:// www.vatican.va/content/john-paul-ii/es/ apost_exhortations/documents/hf_jp-ii_ exh_19811122_familiaris-consortio.html

Mahoney, A. (2010). Religion in Families, 1999 - 2009: A Relational Spirituality Framework. Journal of Marriage and Family 72, 805 - 827. https://doi.org/10.1111/j.1741- 3737.2010.00732.x

Materán, A. (2008). Las representaciones sociales: un referente teórico para la investigación educativa. Geoenseñanza, vol. 13 (2), 243-248. https://www.redalyc.org/ pdf/360/36021230010.pdf

Merino Beas, P. (2010). Diversidad religiosa y teología desde Latinoamérica: visión panorámica. Reflexiones Teológicas, (6), 57-82. https://dialnet.unirioja.es/servlet/ articulo? codigo $=3708983$

Morales, J. (1995). Experiencia religiosa (La contribución de J. H. Newman). Scripta Theologica, 27, (1), 69-91. https://hdl.handle. net/10171/13147

Nieto, J. y Pérez, J. (2020). La escuela católica en Latinoamérica, tránsitos epistemológicos entre una educación reproductiva y una pedagogía crítica para la emancipación. En Pérez, C. Pinto, C. Moncada, J. Nieto y J. Santamaría-Rodríguez (eds.) Reflexiones alrededor de la Iglesia y la educación en el contexto latinoamericano (82-111). Córdoba: Editorial Comunicarte - Editorial Universidad Católica de Córdoba. Recuperado de http://pa.bibdigital.uccor.edu.ar/2181/

Okuda, M. \& Restrepo, C. (2005). Métodos en investigación cualitativa: Triangulación. Revista Colombiana De Psiquiatría, vol. 34 (1). 118-124. https://www.redalyc.org/ pdf/806/80628403009.pdf

Pinto, C. y Nieto, J. (2020). Identidad de la educación católica en América Latina a la luz de las Conferencias Generales del CELAM. En J. Pérez, C. Pinto, C. Moncada, J. Nieto y J. Santamaría-Rodríguez (eds.). Reflexiones alrededor de la Iglesia y la educación en el contexto latinoamericano (40-59). Córdoba: Editorial Comunicarte - Editorial Universidad Católica de Córdoba. Recuperado de http://pa.bibdigital.uccor.edu.ar/2181/

Pulido, S., Castro-Osorio, J., Peña, M. \& ArizaRamírez, D. P. (2013). Pautas, creencias y prácticas de crianza relacionadas con el castigo y su transmisión generacional. Re- 
vista Latinoamericana de Ciencias Sociales, Niñez y Juventud, 11 (1), 245-259. http:// revistaumanizales.cinde.org.co/rlcsnj/index.php/Revista-Latinoamericana/article/ view/849

Rahner, K (1961). Para una teología del símbolo. Escritos de teología, IV. Madrid: Taurus.

Rahner, K. (1964). La Iglesia y los Sacramentos. Barcelona: Herder

Sánchez, M. R. (2018). Las múltiples articulaciones de lo religioso en las intervenciones del trabajo social con abordaje familiar. Religión e Incidencia Pública. Revista de Investigación de GEMRIP, (6), 81-102. Recuperado de: http://religioneincidenciapublica.gemrip. org/wp-content/uploads/2019/03/Sanchez2018-Multiples-Presencias-Religion-Trabajo-Social.pdf

Sánchez Díaz de Rivera, J. (2015). La experiencia religiosa y el sentido de la vida: Una tensión existencial irrenunciable a propósito del diálogo interreligioso. Revista Magistralis, (25), 29-34. Recuperado de https://pdfs.semanticscholar.org/a733/5c55deaeb8db9f9c 459bb716e4b9e775e430.pdf

Salazar Gómez, R., (2012). Carta Pastoral con ocasión de la celebración jubilar de los 450 años de la Arquidiócesis de Bogotá. Bogotá: Instituto San Pablo Apóstol (ISPA).

Schillebeeckx, E. (1971). Cristo, sacramento del encuentro con Dios, $6^{\mathrm{a}}$ ed. Pamplona: Ediciones Dinor

Wojtyla, K. (2011). Persona y acción. Serie Pensa-

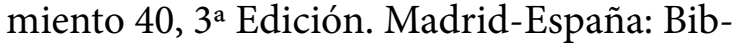
lioteca Palabra.

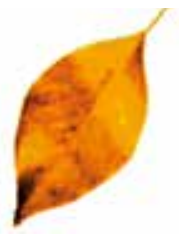

